\title{
Ventromedial Hypothalamic Lesions in Rats Suppress Counterregulatory Responses to Hypoglycemia
}

\author{
Walter P. Borg, * Matthew J. During, ${ }^{\star}$ Robert S. Sherwin, * Monica A. Borg, ${ }^{\star}$ Michael L. Brines, ${ }^{*}$ and Gerald I. Shulman * \\ Yale University School of Medicine, Departments of * Internal Medicine and ${ }^{\ddagger}$ Surgery, New Haven, Connecticut 06510
}

\begin{abstract}
The central nervous system has been implicated in the activation of counterregulatory hormone release during hypoglycemia. However, the precise loci involved are not established. To determine the role of the ventromedial hypothalamic nuclei (VMH) in the hormonal response to hypoglycemia, we performed hypoglycemic clamp studies in conscious SpragueDawley rats with bilateral VMH lesions produced by local ibotenic acid injection $\mathbf{2}$ wk earlier. Rats with lesions in the lateral hypothalamic area, frontal lobe, sham operated (stereotaxic needle placement into hypothalamus without injection), and naive animals served as control groups. The clamp study had two phases. For the first hour plasma glucose was fixed by a variable glucose infusion at euglycemia $(\sim 5.9 \mathrm{mM})$. Thereafter, for an additional $90 \mathrm{~min}$, glucose was either allowed to fall to $(a)$ mild hypoglycemia $(\sim 3.0 \mathrm{mM})$ or $(b)$ more severe hypoglycemia $(\sim 2.5 \mathrm{mM})$. Glucagon and catecholamine responses of lateral hypothalamic area-, frontal lobe-lesioned, sham operated, and naive animals were virtually identical at each hypoglycemic plateau. In contrast, glucagon, epinephrine, and norepinephrine responses in the VMH-lesioned rats were markedly inhibited; hormones were diminished by 50-60\% during mild and by $\mathbf{7 5 - 8 0 \%}$ during severe hypoglycemia as compared with the other groups. We conclude that the VMH plays a crucial role in triggering the release of glucagon and catecholamines during hypoglycemia. (J. Clin. Invest. 1994. 93:16771682.) Key words: ventromedial hypothalamus • hypoglycemia - glucagon • epinephrine • counterregulation
\end{abstract}

\section{Introduction}

The role of the central nervous system (CNS) in the regulation of counterregulatory responses to hypoglycemia remains controversial. Although several lines of evidence strongly implicate the CNS in hypoglycemia detection and counterregulation (13 ), the precise brain regions involved are not known. While various nuclei have been implicated, current data suggest that counterregulatory responses during hypoglycemia are activated, at least in part, via the hypothalamus (4-6). It has been frequently suggested that ventromedial hypothalamus $(\mathrm{VMH}),{ }^{1}$ known as a regulator of food intake ("satiety

Address correspondence to Gerald I. Shulman, M.D., Ph.D., Yale University School of Medicine, Department of Internal Medicine/Endocrinology, 333 Cedar Street, FMP 104, New Haven, CT 06510.

Received for publication 5 October 1993 and in revised form 6 December 1993.

1. Abbreviations used in this paper: FL, frontal lobe; LHA, lateral hypothalamic area; $\mathrm{VMH}$, ventromedial hypothalamus.

\footnotetext{
J. Clin. Invest.

(c) The American Society for Clinical Investigation, Inc.

$0021-9738 / 94 / 04 / 1677 / 06 \$ 2.00$

Volume 93, April 1994, 1677-1682
}

center") $(7,8)$, may also contain glucosensitive tissues that could mediate the responses to hypoglycemia $(9,10)$. This hypothesis was primarily based on the observations that injections of 2-deoxy-glucose into the third ventricle causes hyperglycemia (8). Initially, the VMH was considered a sympathetic center, controlling mainly catecholamine secretion in response to hypoglycemia $(4,11)$; glucagon responses were thought to be triggered by intraislet rather than CNS mechanisms (12, 13). However, Frohman and Bernardis (14) demonstrated that electric stimulation of the $\mathrm{VMH}$ caused an increase in plasma glucagon. This work has been supported by recent studies performed by Biggers et al. (1) and Havel et al. (15). While these studies do not address the role of the VMH during hypoglycemia directly, they do suggest that the VMH could potentially serve as a key center for the activation of hypoglycemic counterregulation. However, since that report, there has been a paucity of data examining this specific issue. Indeed, the relative role of the CNS or extracerebral glucose sensors in initiating counterregulatory responses has remained the subject of controversy.

To determine the role of the VMH nuclei in the hormonal response to hypoglycemia, we combined the hypoglycemic insulin clamp technique with bilateral VMH lesions produced by stereotaxic ibotenic acid injection in Sprague-Dawley rats. Lesions in the lateral hypothalamic area, frontal lobe, sham operated, and nonlesioned (naive) animals served as controls. This approach allowed us to introduce highly specific lesions within the chosen brain region and to test their effect under standardized hypoglycemic conditions.

\section{Methods}

\section{Animals}

Male Sprague-Dawley rats were purchased from Charles River Breeding Laboratories (Wilmington, MA). Animals were housed in an environmentally controlled room with a 12-h light/dark cycle and were maintained on standard ad lib. rat chow (Prolab 3000; AGWAY, Waverley, NY) comprising of $22 \%$ protein, $5 \%$ fat, and $51 \%$ carbohydrate (the remaining $22 \%$ consists of ash, crude fiber, and moisture).

\section{Lesions}

Rats (mean body wt $\sim 290 \mathrm{~g}$, range $270-310 \mathrm{~g}$ ) were anesthetized by intraperitoneal injection $(1 \mathrm{ml} / \mathrm{kg}$ ) of a mixture of xylazine $(20 \mathrm{mg} /$ $\mathrm{ml}$ ) (AnaSed; Lloyd Laboratories, Shenandoah, IA) and ketamine $(100 \mathrm{mg} / \mathrm{ml})$ (Ketaset; Aveco Co., Fort Dodge, IA) in a ratio of $1: 2$ (vol:vol). Thereafter, they received bilateral stereotaxic infusions of $0.12 \mathrm{M}$ ibotenic acid (Research Biochemicals Inc., Natick, MA) dissolved in a sterile artificial extracellular fluid solution $(\mathrm{NaCl} 135 \mathrm{mM}$, $\mathrm{KCl} 3 \mathrm{mM}, \mathrm{MgCl}_{2} 1 \mathrm{mM}, \mathrm{CaCl}_{2} 1.2 \mathrm{mM}$, ascorbate $200 \mu \mathrm{M}$, and a sodium phosphate buffer of $2 \mathrm{mM}$ to $\mathrm{pH}$ 7.4) (16). The solution was infused at a rate of $0.25 \mu \mathrm{l} / \mathrm{min}$. The needle was placed with the beveling directed anteriorly, and $0.5 \mu \mathrm{l}$ of ibotenic acid was infused, then beveling of the needle was reversed, and $0.5 \mu \mathrm{l}$ was infused into posterior directions. The needle was left inside the tissue for a 3-min period, to allow diffusion and to prevent backflow of ibotenic acid through the 
needle track. All stereotaxic coordinates were determined from the atlas of Paxinos and Watson (17). Five different groups of animals were prepared as follows.

Group 1. VMH-lesioned rats were injected at points located $2.5 \mathrm{~mm}$ posterior, $0.6 \mathrm{~mm}$ lateral in relation to bregma, and $9.6 \mathrm{~mm}$ below the horizontal plane passing through bregma and lambda.

Group 2. Frontal lobe (FL)-lesioned rats were injected using the coordinates: $2.0 \mathrm{~mm}$ anterior, $2.0 \mathrm{~mm}$ lateral in relation to bregma, and $2.0 \mathrm{~mm}$ below the horizontal plane passing through bregma and lambda.

Group 3. Lateral hypothalamic area (LHA)-lesioned rats were injected using the coordinates: $2.0 \mathrm{~mm}$ posterior, $2.0 \mathrm{~mm}$ lateral in relation to bregma, and $8.4 \mathrm{~mm}$ below the horizontal plane passing through bregma and lambda.

Group 4. Sham operated animals were prepared by lowering the injection needle in the proximity of VMH using the coordinates 2.5 $\mathrm{mm}$ posterior, $0.6 \mathrm{~mm}$ lateral in relation to bregma, and $8.6 \mathrm{~mm}$ below the horizontal plane passing through bregma and lambda, but no toxin was infused.

Group 5. Control (naive) animals did not receive any surgery. Lesioned animals were studied 12-16 d after the stereotaxic procedure. At the end of the experiments, lesion placement was verified histologically by cresyl violet staining. Lesions were identified as areas of neuronal loss. Only the animals that showed bilateral destruction of the desired brain regions were included. From all animals studied, in the mild hypoglycemia group $11 \%$ of VMH and $29 \%$ of LHA did not meet the histological criteria. In the severe hypoglycemia group $16 \%$ of $\mathrm{VMH}$ were excluded. All other animals studied met histological criteria.

\section{Surgical procedures}

At 6-10 d before the study and 7-9 d after stereotaxic surgery, animals underwent an additional aseptic surgical procedure for placement of internal jugular vein and carotid artery catheters under intraperitoneal pentobarbital anesthesia (Nembutal $35 \mathrm{mg} / \mathrm{kg}$ body wt; Abbott Laboratories, North Chicago, IL). The polyethylene carotid artery catheter was extended to the level of the aortic arch, and the silicone internal jugular vein catheter was advanced to the level of the right atrium. At the end of the procedure both catheters were flushed and filled with heparin $(42 \mathrm{U} / \mathrm{ml})$ and polyvinylpyrrolidone $(1.7 \mathrm{~g} / \mathrm{ml})$ solution, plugged, tunneled subcutaneously around the side of the neck, and externalized behind the head through a skin incision. Catheters remained sealed until the day of the study. Only those animals that had recovered completely and showed no signs of infection within $36 \mathrm{~h}$ after surgery were used.

\section{Euglycemic/hypoglycemic clamp}

The hyperinsulinemic glucose clamp technique, as adapted for the rat (18), was used to provide a fixed hypoglycemic stimulus. Two sets of experiments were performed: In the first, all five groups of animals were studied, and the plasma glucose concentration was lowered to $\sim 3.0 \mathrm{mM}$. In the second, only VMH-lesioned and naive (control) animals were studied, and a more severe hypoglycemic stimulus $(\sim 2.5 \mathrm{mM})$ was produced.

The rats were fasted for $\sim 24 \mathrm{~h}$ before the study. On the morning of the experiment, the catheters were flushed with saline and maintained patent by a slow infusion of saline $(20 \mu \mathrm{l} / \mathrm{min})$ that contained a small amount of heparin ( $1-2 \mathrm{U} / \mathrm{ml})$. Animals were fully awake and freely moving about in their cages, untethered. After a 60-min rest period, blood samples were withdrawn for measurement of baseline glucose, insulin, glucagon, epinephrine, and norepinephrine concentration. Thereafter, a primed $(2,160 \mathrm{pmol}$ over $1.5 \mathrm{~min})$ continuous infusion $\left(120 \mathrm{pmol} / \mathrm{kg}^{-1} \cdot \mathrm{min}^{-1}\right.$ ) of porcine insulin (Eli Lilly \& Co., Indianapolis, IN) was initiated and maintained for $150 \mathrm{~min}$. A variable infusion of exogenous glucose was adjusted based on plasma glucose measurements obtained at 5-min intervals to achieve the desired glucose level. During the first $60 \mathrm{~min}$, the rats were maintained at euglycemia (mean plasma glucose $\sim 5.9 \mathrm{mM})$. Thereafter, plasma glucose was allowed to fall to hypoglycemic levels $(\sim 3.0 \mathrm{mM}$ for the first set or $\sim 2.5 \mathrm{mM}$ for the second set of experiments) and maintained there for $90 \mathrm{~min}$. Experiments were terminated if the plasma glucose $(a)$ fell below $4.5 \mathrm{mM}$ during the last $45 \mathrm{~min}$ of the euglycemic phase, $(b)$ rose above $3.9 \mathrm{mM}$ (secondary to glucose infusion), or $(c)$ inadvertently fell below $2.0 \mathrm{mM}$ during the hypoglycemic phase. Only the studies during which the mean blood glucose level achieved during hypoglycemia was in the range of $2.8-3.1 \mathrm{mM}$ (for the first set) or 2.2-2.5 mM (for the second set) were analyzed. In the mild hypoglycemia group $18 \%$ of FL properly lesioned (as verified histologically) and $40 \%$ of naive animals did not meet these criteria. In the severe hypoglycemia group $16 \%$ of control studies (naive rats) were excluded. Histological results and the accuracy of the clamps were the only criteria for excluding or including the clamp studies for the data analysis; exclusions were never made based on the knowledge of the hormonal results.

Blood samples for measurements of glucagon, epinephrine, and insulin were taken during the euglycemic (30- and 60-min) and hypoglycemic (90-, 120-, 135-, and 150-min) phases of the experiments. During blood sampling, sample dilution by fluid in the dead space of the catheter was avoided by withdrawal of $0.5 \mathrm{ml}$ of blood before sample collection. This volume exceeded the dead space volume by about fivefold. A new syringe was then used for sample collection. Subsequently, the initial syringe was reattached, and the contents reinfused. Blood obtained from littermates at least 30 min before the study was transfused during the clamp to quantitatively replace blood withdrawn during the experiment. The protocol was reviewed and approved by the Yale Animal Care and Use Committee.

\section{Analytical methods and calculations}

Plasma glucose was measured in duplicate using a Glucose Analyzer II (Beckman Instruments Inc., Fullerton, CA). Plasma insulin (Binax, South Portland, MA), and glucagon (ICN Biomedicals, Inc., Carson, CA) using porcine standard were determined by a double antibody radioimmunoassay. Insulin measurements during the basal and insulin infusion periods were made using rat and porcine standards, respectively. Plasma catecholamines were measured with a radioenzymatic method (Amersham Corp., Arlington Heights, IL).

Data are expressed as mean \pm SE. Comparison between the study groups was made by ANOVA with a repeated measure design, followed by the Student's $t$ test to localize effects. Glucose infusion rates during the hypoglycemic steps represent the average values during the designated time interval.

\section{Results}

Set 1: mild hypoglycemia. As summarized in Table I, basal glucose, insulin, glucagon, epinephrine, and norepinephrine levels were not significantly different between any of the study groups. The average weight of the animals on the day of the study was $290 \pm 10 \mathrm{~g}$ (VMH), $250 \pm 5 \mathrm{~g}$ (LHA), 290 $15 \mathrm{~g}$ (FL), $290 \pm 5$ ( sham operated), and $290 \pm 10 \mathrm{~g}$ (naive). The weight of the LHA-lesioned animals was significantly lower as compared with other groups $(P<0.05)$. During the insulin infusion, plasma insulin rose to nearly identical levels, and plasma glucose was indistinguishable during each phase of the study in all groups (Table II). During the hypoglycemic phase of the study, the desired level of glycemia (i.e., $3.0 \mathrm{mM}$ ) was achieved in the first $30 \mathrm{~min}$. When euglycemia ( $5.9 \mathrm{mM}$ ) was maintained, the concentrations of glucagon and norepinephrine were not different between the studied groups, whereas during the euglycemic phase, plasma epinephrine was significantly decreased in the VMH-lesioned animals as compared with other groups $(0.3 \pm 0.01 \mathrm{nM}$ [ $\mathrm{VMH}$ ] vs $0.9 \pm 0.1$ [LHA], $0.7 \pm 0.1$ [FL], $0.9 \pm 0.1$ [sham operated], $0.8 \pm 0.2 \mathrm{nM}$ [ naive]; $P<0.05$ ).

The effects of VMH lesions on hormonal counterregulatory responses to mild hypoglycemia $(3.0 \mathrm{mM})$ are depicted in Fig. 1. Despite a comparable hypoglycemic stimulus, epinephrine, 
Table I. Basal Characteristics of the Animals Studied

\begin{tabular}{|c|c|c|c|c|c|}
\hline & $\begin{array}{c}\text { VMH } \\
(n=8)\end{array}$ & $\begin{array}{c}\mathrm{FL} \\
(n=9)\end{array}$ & $\begin{array}{l}\text { Naive } \\
(n=6)\end{array}$ & $\begin{array}{c}\text { LHA } \\
(n=5)\end{array}$ & $\begin{array}{l}\text { Sham operated } \\
\quad(n=5)\end{array}$ \\
\hline \multicolumn{6}{|l|}{ Insulin } \\
\hline$(n M)$ & $0.1 \pm 0.04$ & $0.1 \pm 0.02$ & $0.1 \pm 0.02$ & $0.1 \pm 0.02$ & $0.1 \pm 0.05$ \\
\hline \multicolumn{6}{|l|}{ Glucagon } \\
\hline (ng/liter) & $136 \pm 24$ & $122 \pm 16$ & $112 \pm 10$ & $201 \pm 51$ & $191 \pm 8$ \\
\hline \multicolumn{6}{|l|}{ Epinephrine } \\
\hline$(n M)$ & $0.6 \pm 0.1$ & $0.8 \pm 0.2$ & $0.8 \pm 0.3$ & $0.4 \pm 0.2$ & $0.7 \pm 0.2$ \\
\hline \multicolumn{6}{|c|}{ Norepinephrine } \\
\hline$(n M)$ & $0.9 \pm 0.2$ & $1.4 \pm 0.2$ & $1.3 \pm 0.2$ & $1.2 \pm 0.2$ & $1.1 \pm 0.2$ \\
\hline
\end{tabular}

norepinephrine, and glucagon responses in the VMH-lesioned rats were significantly blunted (by $\sim 50-60 \%$ ) compared with the other groups $(P<0.05)$. LHA-lesioned, FL-lesioned, sham operated, and naive animals showed indistinguishable hormonal responses to mild hypoglycemia (Fig. 1).

The diminished hormonal response in the VMH-lesioned rats was associated with a higher glucose infusion rate required to maintain the $3.1 \mathrm{mM}$ hypoglycemic plateau during the final $30 \mathrm{~min}$ of the study $\left(13.8 \pm 1.3 \mathrm{mg} / \mathrm{kg}^{-1} \cdot \mathrm{min}^{-1}[\mathrm{VMH}]\right.$ vs $5.2 \pm 0.7$ [LHA], $6.9 \pm 0.7$ [FL], 5.8 \pm 1.0 [sham-operated], $7.0 \pm 1.4 \mathrm{mg} / \mathrm{kg}^{-1} \cdot \mathrm{min}^{-1}$ [naive]; $P<0.05$ ).

Set 2: severe hypoglycemia. To determine if the diminished hormonal responses during hypoglycemia seen in VMH-lesioned animals persisted with a stronger hypoglycemic stimulus, plasma glucose was lowered to $2.5 \mathrm{mM}$. The average weight of the VMH and naive animals on the day of study was $295 \pm 10$ and $270 \pm 5 \mathrm{~g}$, respectively. As in set 1, during the insulin infusion plasma insulin rose to nearly identical levels, and plasma glucose was indistinguishable during each phase of the study in the two groups (Table III). During the hypoglycemic phase of the study, the desired level of glycemia (i.e., $2.5 \mathrm{mM}$ ) was achieved in the first $30 \mathrm{~min}$. As shown in Fig. 2, VMH lesions caused a marked reduction in peak elevations of circulating glucagon $(241 \pm 45 \mathrm{ng} /$ liter [VMH] vs $796 \pm 112 \mathrm{ng} /$ liter in naive animals, $P<0.01$ ), epinephrine $(12.8 \pm 0.9 \mathrm{nM}$ [ VMH] vs $69.3 \pm 4.1 \mathrm{nM}$ in naive animals, $P<0.01$ ), and norepinephrine $(3.3 \pm 0.4 \mathrm{nM}$ [ VMH] vs $45.1 \pm 4.5 \mathrm{nM}$ in naive animals, $P$ $<0.01$ ) in response to the $2.5 \mathrm{mM}$ hypoglycemic plateau.

In keeping with this finding, the VMH-lesioned animals required a higher glucose infusion rate to maintain plasma glucose at $2.5 \mathrm{mM}$ during the final $30 \mathrm{~min}$ of the hypoglycemic step $\left(3.0 \pm 0.7 \mathrm{mg} / \mathrm{kg}^{-1} \cdot \mathrm{min}^{-1}[\mathrm{VMH}]\right.$ vs $1.1 \pm 0.2 \mathrm{mg} /$ $\mathrm{kg}^{-1} \cdot \mathrm{min}^{-1}$ in naive animals, $\left.P<0.05\right)$.

\section{Discussion}

The current data demonstrate that bilateral selective lesions of the VMH produce striking reductions in the magnitude of the glucagon, epinephrine, and norepinephrine responses to both mild and moderately severe hypoglycemia. Neither sham surgery nor selective lesions of the LHA or the FL had such an effect.

Whereas the role of individual counterregulatory hormones in hypoglycemia correction has been studied extensively (1922 ), the mechanisms that link glucopenia with activation of the counterregulatory system are poorly understood. There is much controversy concerning the tissues that sense glucopenia and coordinate the counterregulatory responses. In fact, numerous neural centers have been proposed to control counterregulatory hormone release $(2,23)$. The hypothalamus has long been considered a potential center for the integration of the hypoglycemia-induced adrenergic response (4, 24-26). Studies have implicated the ventromedial portion of this brain region, in particular. However, the role of the VMH in modulating counterregulatory hormone release has never been directly tested under hypoglycemic conditions. Rather, it has been shown that electrical or mechanical stimulation of the VMH caused hyperglycemia $(25,27,28)$. Moreover, injection of 2deoxy-glucose into the third ventricle also resulted in hyperglycemia $(8,29)$. However, this does not localize the locus for the counterregulatory response to hypoglycemia specifically to the VMH. Interestingly, in contrast to traditional opinion that

Table II. Mean Plasma Glucose and Insulin Concentrations during Mild Hypoglycemia

\begin{tabular}{|c|c|c|c|c|c|}
\hline & $\begin{array}{c}\text { VMH } \\
(n=8)\end{array}$ & $\begin{array}{c}\mathrm{FL} \\
(n=9)\end{array}$ & $\begin{array}{l}\text { Naive } \\
(n=6)\end{array}$ & $\begin{array}{c}\text { LHA } \\
(n=5)\end{array}$ & $\begin{array}{c}\text { Sham operated } \\
\quad(n=5)\end{array}$ \\
\hline \multicolumn{6}{|l|}{ Euglycemia } \\
\hline Glucose $(m M)$ & $5.8 \pm 0.2$ & $5.9 \pm 0.1$ & $5.9 \pm 0.1$ & $5.9 \pm 0.2$ & $5.8 \pm 0.2$ \\
\hline Insulin $(n M)$ & $4.9 \pm 0.6$ & $4.7 \pm 0.7$ & $4.7 \pm 0.5$ & $5.0 \pm 0.6$ & $4.8 \pm 0.6$ \\
\hline \multicolumn{6}{|l|}{ Hypoglycemia } \\
\hline Glucose $(m M)$ & $2.9 \pm 0.1$ & $3.0 \pm 0.1$ & $3.0 \pm 0.1$ & $2.9 \pm 0.2$ & $2.9 \pm 0.2$ \\
\hline Insulin $(n M)$ & $5.0 \pm 0.6$ & $4.8 \pm 0.4$ & $4.9 \pm 0.4$ & $5.0 \pm 0.5$ & $4.9 \pm 0.4$ \\
\hline
\end{tabular}

Glucose values were obtained by averaging all glucose measurements during the euglycemic or hypoglycemic phases of the study. Insulin data for the euglycemic phase represent the average insulin level of the samples obtained at the end of this phase. Insulin values during hypoglycemia represent the average of measurements obtained at 90 and $150 \mathrm{~min}$. 


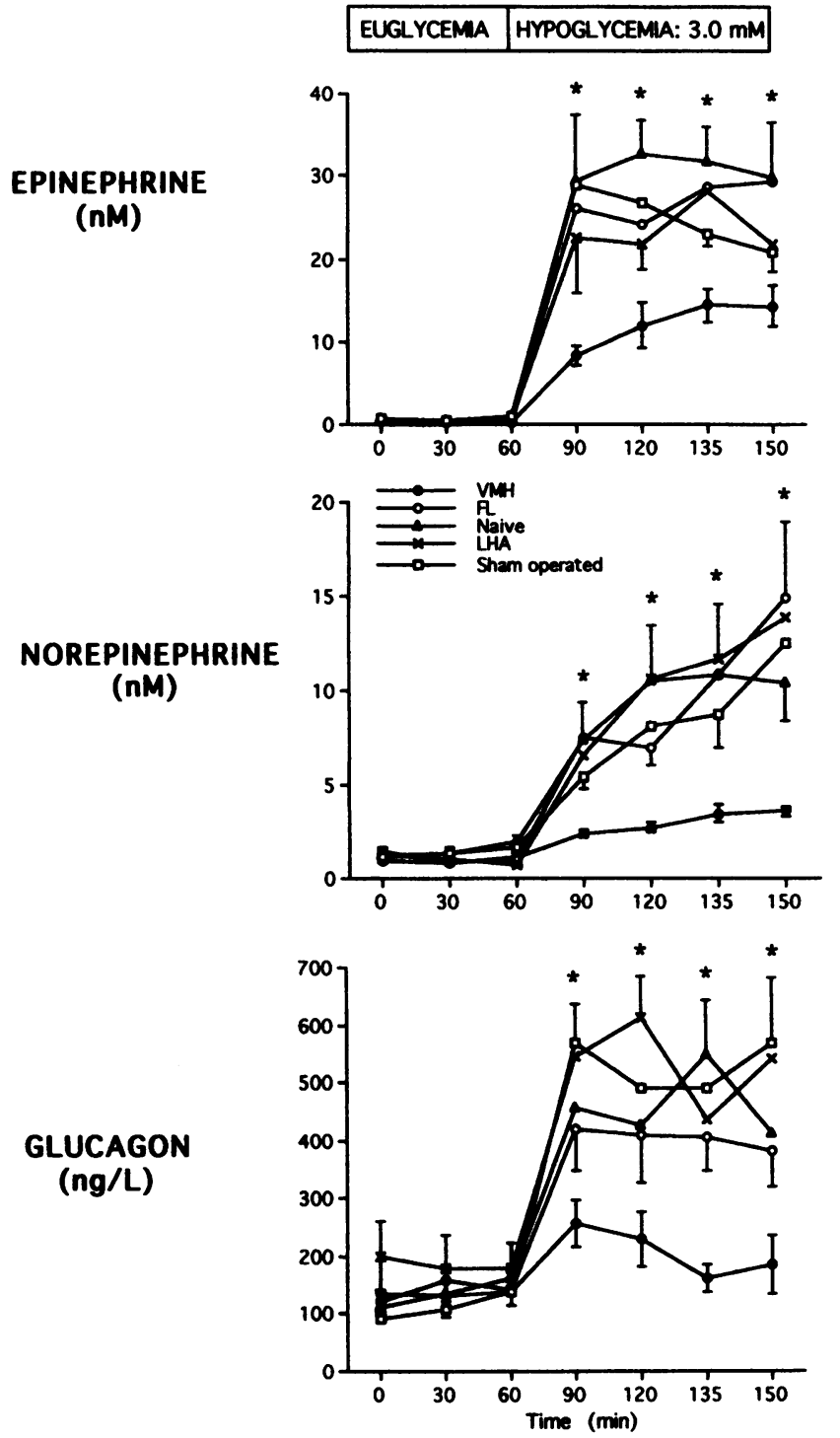

Figure 1. Effect of VMH lesioning on counterregulatory hormone response to mild ( $3.0 \mathrm{mM})$ hypoglycemia. The asterisk denotes significant statistical difference as compared with all control groups $(P$ $<0.05)$.

only catecholamine release is critically dependent upon the CNS (2), electrical stimulation of the VMH in rats has been found to cause an increase in plasma glucagon concentration (14), consistent with evidence that efferents from the ventral

Table III. Mean Plasma Glucose and Insulin Concentrations during Severe Hypoglycemia

\begin{tabular}{ccc}
\hline & $\begin{array}{c}\text { VMH } \\
(n=5)\end{array}$ & $\begin{array}{c}\text { Naive } \\
(n=5)\end{array}$ \\
\hline Euglycemia & & \\
$\quad$ Glucose $(m M)$ & $5.7 \pm 0.3$ & $5.8 \pm 0.2$ \\
$\quad$ Insulin $(n M)$ & $4.6 \pm 0.5$ & $4.7 \pm 0.6$ \\
Hypoglycemia & & \\
$\quad$ Glucose $(m M)$ & $2.5 \pm 0.1$ & $2.6 \pm 0.2$ \\
Insulin $(n M)$ & $4.7 \pm 0.5$ & $4.8 \pm 0.8$ \\
\hline
\end{tabular}

Glucose and insulin data were obtained as indicated in Table II.

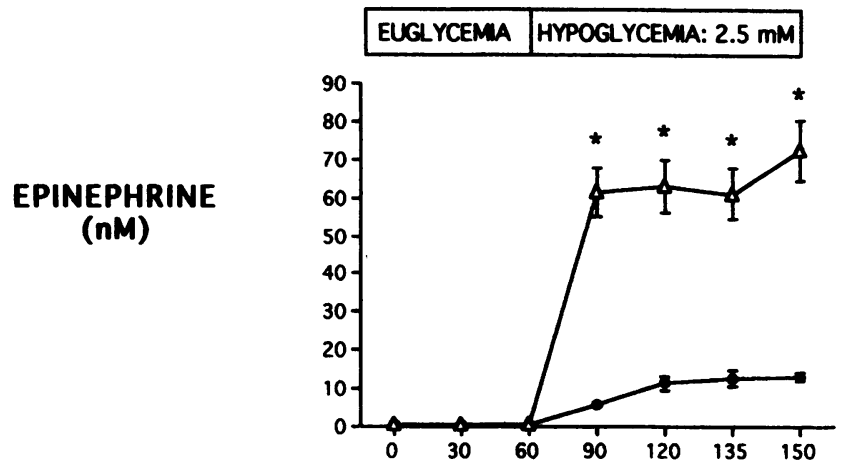

NOREPINEPHRINE (nM)

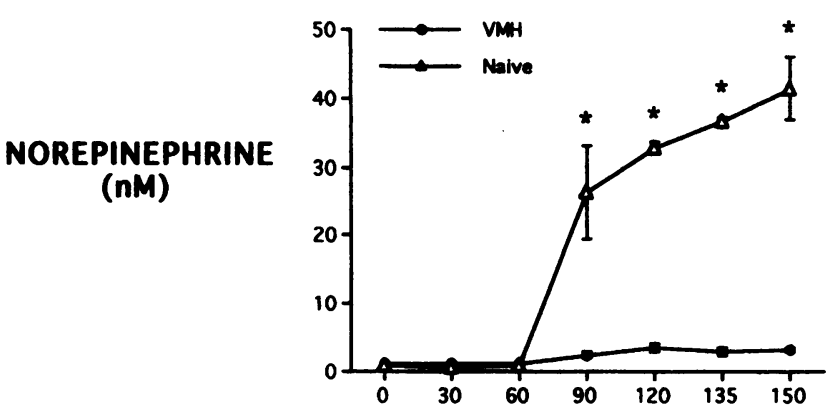

\section{GLUCAGON \\ (ng/L)}

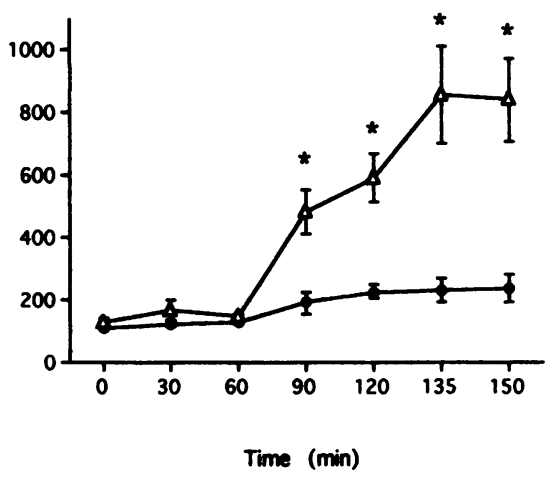

Figure 2. Effect of VMH lesioning on counterregulatory hormone response to severe $(2.5 \mathrm{mM})$ hypoglycemia. The asterisk denotes significant statistical difference as compared with all control groups ( $P$ $<0.01)$.

region of the hypothalamus impinge on the endocrine pancreas (30).

It should be noted, however, that some data do not support the concept that the neurons controlling the response to glucopenia reside in the VMH. In fact, it has been suggested that they are not located in the forebrain (which comprises cerebral hemispheres, thalamus, subthalamus, hypothalamus, and epithalamus). Cantu et al. (31) reported finding glucoreceptors located within the spinal cord that are capable of augmenting catecholamine secretion during hypoglycemia. Goldfien et al. (32) also concluded that there are similar centers in the cervical portion of the spinal cord. In keeping with this conclusion DiRocco and Grill (33) have demonstrated that the sympathetic response to systemic 2-deoxy-D-glucose was not prevented by complete decerebration of the rat. Ritter et al. (34) showed that the obstruction of the cerebral aqueduct (that connects the fourth ventricle located in the hindbrain with third and lateral ventricles situated in the forebrain) failed to sup- 
press the hyperglycemic response to 5-thioglucose injected into the fourth ventricle. Furthermore, under these conditions the hyperglycemic response to 5-thioglucose injection into third ventricle was abolished. From these data authors concluded that glucoreceptors are located in the hindbrain (which consists of pons and medulla oblongata ) and not in the hypothalamus. This view is consistent with data generated by Cane et al. (35), who reported that counterregulatory responses were not inhibited when glucose was infused in the carotid arteries to abolish forebrain hypoglycemia during systemic hypoglycemia. However, these results may not exclude an important role for hypothalamic glucoreceptors. Studies performed by Biggers et al. (1) and more recently by Frizzell et al. (36) demonstrated that bilateral infusion of glucose into the carotid as well as vertebral arteries suppressed counterregulatory hormone responses to peripheral hypoglycemia. Thus, it is still plausible that the hypothalamus plays a role in hypoglycemia detection or in integration of information generated from glucoreceptors localized elsewhere (37-39).

Controversy surrounding the loci responsible for triggering hypoglycemia-induced counterregulation may at least in part be methodology related. Firstly, in many studies, nonphysiologic stimuli were used to generate cellular glucopenia, such as the use of systemically administered metabolic inhibitors. The degree of glucopenia with 2-deoxy-D-glucose is difficult to control and therefore difficult to relate to physiologic hypoglycemia. Secondly, it is very difficult to interpret data generated by transecting the brain or spinal cord at different levels in experimental animals $(31,40)$. The operative separation of the hypothalamus from the lower centers causes a marked and persistent increase in the basal secretion rate of epinephrine, and in turn, hyperglycemia $(31,40)$. Moreover, epinephrine secretion is increased further when the blood glucose level declines under the influence of insulin, even before the normal fasting level of glucose is restored $(31,40)$. In contrast in the normal animal, there is a definite level of blood glucose, well below fasting glucose concentration, at which epinephrine release abruptly begins (41). Thus, neuroaxis transection itself produces an abnormal condition, promoting nonspecific release of epinephrine.

In our study, we have attempted to overcome potential limitations of earlier studies. The sequential euglycemic-hypoglycemic glucose clamp technique was used to control glucose levels, providing more physiological and reproducible stimuli between studied groups. Selective chemical lesioning technique was used to destroy the specific neural regions. Chemical lesioning with ibotenic acid, a glutamate analogue, is superior to classical (electric and mechanical) lesioning procedures since it destroys selectively neuronal cell bodies without affecting fibers of passage (42). This method also diminished the confounding effect of simple surgical brain stem dissection on catecholamine secretion. In our experiments, no basal hyperglycemia, hyperadrenalemia, or hyperglucagonemia was observed in the LHA-, FL-lesioned, or sham operated groups as compared with the normal animals. Quite surprisingly, a significant decrease in the epinephrine level was noted in VMH-lesioned rats during euglycemic phase of the study. This suggests that a tonic activity of $\mathrm{VMH}$ under euglycemic hyperinsulinemic condition is necessary to maintain blood epinephrine concentration on the basal level. Potential nonspecific effect of ibotenic acid on counterregulation was excluded since neither LHA- nor FL-lesioned animals showed any defect in hormonal counterregulatory responses. It is noteworthy that chemical lesions located in hypothalamus (LHA), but outside VMH, failed to change the counterregulatory response. Finally, sham operations, which included all manipulation involved in the chemical lesioning of VMH except ibotenic acid infusions, had no effect on counterregulatory response.

In summary, the current studies demonstrate a profound decrease in the magnitude of hormonal counterregulation after selective lesioning of the VMH. These data suggest that the neurons located in VMH are essential for the integrated hormonal response to glucose deprivation. However, it should be emphasized that our studies cannot answer the question if glucosensors are located in the neurons of VMH. The specific role of these neurons in detection of hypoglycemia and/or coordinating counterregulatory response remains to be established.

\section{Acknowledgments}

We appreciate the assistance of Aida Groszmann and Andrea Belous for their help in the measurements of plasma hormones. We also gratefully acknowledge Jeffrey Tamborlane and Nicole Hamlet for their expert technical assistance.

This research was supported by grants from the U.S. Public Health Service (DK-20495, DK-40936, DK-45735, and NS-28227) and a fellowship grant from The Juvenile Diabetes Foundations International (W. P. Borg).

\section{References}

1. Biggers, D. W., S. R. Myers, D. Neal, R. Stinson, N. B. Cooper, J. B. Jaspan, P. E. Williams, A. D. Cherrington, and R. T. Frizzel. 1989. Role of brain in counterregulation of insulin-induced hypoglycemia in dogs. Diabetes. 37:7-16.

2. Woods, S. C., and D. Porte, Jr. 1974. Neural control of the endocrine pancreas. Physiol. Rev. 54:596-619.

3. Bloom, S. R., A. V. Edwards, and N. J. Vaughan. 1974. The role of the autonomic innervation in the control of glucagon release during hypoglycaemia in the calf. J. Physiol. (Lond.). 236:611-623.

4. Himsworth, R. L. 1970. Hypothalamic control of adrenaline secretion in response to insufficient glucose. J. Physiol. (Lond.). 206:411-417.

5. Niijima, A., H. Kannan, and H. Yamashita. 1988. Neural control of blood glucose homeostasis: effect of microinjection of glucose into hypothalamic nuclei on efferent activity of pancreatic branch of vagus nerve in the rat. Brain Res. Bull. 20:811-815.

6. Shmizu, N., Y. Oomura, D. Novin, C. V. Grijava, and P. H. Cooper. 1983. Functional correlation between lateral hypothalamic glucose-sensitive neurons and hepatic portal glucose-sensitive units in rat. Brain Res. 265:49-54.

7. Hetherington, A. W., and S. W. Ranson. 1942. The spontaneous activity and food intake of rats with hypothalamic lesions. Am. J. Physiol. 136:609-617.

8. Oomura, Y., K. Kimura, H. Ooyama, T. Maeo, M. Iki, and N. Kuniyoshi. 1964. Reciprocal activities of ventromedial and lateral hypothalamic areas of cats. Science (Wash. DC). 143:484-485.

9. Benzo, C. A. 1983. The hypothalamus and blood glucose regulation. Life Sci. 32:2509-2515.

10. Szabo, O., and A. J. Szabo. 1975. Studies on the nature and mode of action of the insulin-sensitive glucoreceptor in the central nervous system. Diabetes. 24:328-336.

11. Barris, R. W., and W. R. Ingram. 1936. The effect of experimental hypothalamic lesions upon blood sugar. Am. J. Physiol. 114:555-561.

12. Palmer, J., D. Henry, J. Benson, D. Johnson, and J. Ensinck. 1976. Glucagon response to hypoglycemia in sympathectomized man. J. Clin. Invest. 57:522-525.

13. Palmer, J., P. Werner, P. Hollander, and J. Ensinck. 1979. Evaluation of the control of glucagon secretion by the parasympathetic nervous system in man. Metab. Clin. Exp. 28:549-552.

14. Frohman, L. A., and L. L. Bernardis. 1971. Effect of hypothalamic stimulation on plasma glucose, insulin, and glucagon levels. Am. J. Physiol. 221:15961603.

15. Havel, P. J., R. C. Veith, B. E. Dunning, and G. E. Taborsky. 1991. Role for autonomic nervous system to increase pancreatic glucagon secretion during market insulin induced hypoglycemia in dogs. Diabetes. 40:1107-1114.

16. During, M. J. 1991. In vivo neurochemistry of the conscious human brain: intrahippocampal microdialysis in epilepsy. In Microdialysis in the Neuro- 
sciences. T. E. Robinson and J. B. Justice, Jr., editors. Elsevier Science Publishers B. V., Amsterdam. 425-442.

17. Paxinos, G., and C. Watson. 1991. The Rat Brain in Stereotaxic Coordinates. 2nd ed. Academic Press Inc., New York. 262 pp.

18. Rossetti, L., D. Smith, G. I. Shulman, D. Papachristou, and R. A. DeFronzo. 1987. Correction of hyperglycemia with phlorizin normalizes tissue sensitivity to insulin in diabetic rats. J. Clin. Invest. 79:1510-1515.

19. Gerich, J., J. Davis, M. Lorenzi, R. Rizza, N. Bohannon, J. Karam, S. Levis, R. Kaplan, T. Schultz, and P. Cryer. 1979. Hormonal mechanisms of recovery from insulin-induced hypoglycemia in man. Am. J. Physiol. 236:E380385. 264.

20. Cryer, P. E. 1981. Glucose counterregulation in man. Diabetes. 30:261-

21. Polinsky, R. J., I. J. Kopin, M. H. Ebert, and V. Weise. 1980. The adrena medullary response to hypoglycemia in patients with orthostatic hypotension. $J$. Clin. Endocrinol. \& Metab. 51:1401-1406.

22. Rizza, R. A., P. E. Cryer, and J. E. Gerich. 1979. Role of glucagon, catecholamines, and growth hormone in human glucose counterregulation. $J$. Clin. Invest. 64:62-71.

23. Niijima, A. 1989. Neural mechanisms in the control of blood glucose concentration. J. Nutr. 119:833-840.

24. Anand, B. K., G. S. Chhina, K. N. Sharma, S. Dua, and B. Singh. 1964 Activity of single neurons in the hypothalamic feeding centers: effect of glucose. Am. J. Physiol. 207:1146-1154.

25. Gisel, E. G., and D. L. Innes. 1979. Glycemic responses induced by hypothalamic stimulation. Neuroendocrinology. 28:212-216.

26. Frohman, L. A., and K. Nagai. 1976. Central nervous system-mediated stimulation of glucagon secretion in the dog following 2-deoxyglucose. Metab. Clin. Exp. 25:1449-1452.

27. Bernard, C. 1858. Lecons sur la Physiologie et la Pathologie en Systeme Nerveux. Editions J.-B. Baillière, Paris. 549-555.

28. Shimazu, T., H. Matsushita, and L. Kshikawa. 1978. Hypothalamic control of liver glycogen metabolism in adult and aged rats. Brain Res. 144:343-352.

29. Molina, P. E., K. Eltayeb, H. Hourani, K. Okamura, L. B. Nanney, P. Williams, and N. N. Abumrad. 1993. Hormonal and metabolic effects of neuroglucopenia. Brain Res. 614:99-108.
30. Miller, R. E. 1981. Pancreatic neuroendocrinology: peripheral neural mechanisms in the regulation of the islets of Langerhans. Endocr. Rev. 2:471494.

31. Cantu, R. C., J. W. Corelli, and W. M. Manager. 1968. Reassessment of central neural pathways necessary for adrenal catecholamine output in response to hypoglycemia. Proc. Soc. Exp. Biol. Med. 129:155-161.

32. Goldfien, A., K. S. Gullixson, and G. Hargrove. 1966. Evidence for centers in the central nervous system that regulate fat mobilisation in dogs. $J$. Lipid Res. 7:357-367.

33. DiRocco, R. J., and H. J. Grill. 1979. The forebrain is not essential for sympathoadrenal hyperglycemic response to glucoprivation. Science (Wash. DC). 204:1112-1114.

34. Ritter, R. C., P. G. Slusser, and S. Stone. 1981. Glucoreceptors controlling feeding and blood glucose: location in the hindbrain. Science (Wash. DC) 213:451-453.

35. Cane, P., R. Artal, and R. N. Bergman. 1985. Putative hypothalamic glucoreceptors play no essential role in the response to moderate hypoglycemia. Diabetes. 35:268-277.

36. Frizzell, R. T., E. M. Jones, S. N. Davis, D. W. Biggers, S. R. Myers, C. C. Connolly, D. W. Neal, J. B. Jaspan, and A. D. Cherrington. 1993. Counterregulation during hypoglycemia is directed by widespread brain regions. Diabetes. 42:1253-1261.

37. Niijima, A. 1980. Glucose sensitive afferent nerve fibers in the liver and regulation of blood glucose. Brain Res. Bull. 5(Suppl. 4):175-179.

38. Lautt, W. W. 1980. Hepatic nerves: a review of their functions and effects. Can. J. Physiol. Pharmacol. 58:105-123.

39. Russek, M. 1963. Participation of hepatic glucoreceptors in the control of food intake. Nature (Lond.). 197:79-80.

40. Crone, C. 1965. The secretion of adrenal medullary hormones during hypoglycaemia in intact, decerebrate and spinal sheep. Acta Physiol. Scand. 63:213-224.

41. Armin, J., and R. T. Grant. 1959. Adrenaline release during insulin hypoglycaemia in the rabbit. J. Physiol. (Lond.). 149:228-249.

42. Coyle, J. T., M. E. Molliver, and M. J. Kuhar. 1978. In situ injection of kainic acid: a new method for selectively lesioning neuronal cell bodies while sparing axons of passage. J. Comp. Neurol. 180:301-324. 